\title{
Mapping the structure of knowledge for teaching nominal categorical data analysis
}

Randall E. Groth (corresponding author) and Jennifer A. Bergner

1101 Camden Ave., Salisbury, MD 21801 USA

Salisbury University

Phone: 1-410-677-5061

Fax: 1-410-677-0249

Email: regroth@salisbury.edu

Abstract: This report describes a model for mapping cognitive structures related to content knowledge for teaching. The model consists of knowledge elements pertinent to teaching a content domain, the nature of the connections among them, and a means for representing the elements and connections visually. The model is illustrated through empirical data generated as prospective teachers were in the process of developing knowledge for teaching nominal categorical data analysis. During a course focused on the development of statistical knowledge for teaching, the prospective teachers analyzed statistical problems, descriptions of children's statistical thinking, and related classroom scenarios. Their analyses suggested various types of knowledge structures in development. In some cases, they constructed all knowledge elements targeted in the course. In many cases, however, their knowledge structures had missing, incompatible, and/or disconnected elements preventing them from carrying out recommendations for teaching elementary nominal categorical data analysis in an optimal manner. The report contributes to teacher education by drawing attention to prospective teachers' learning needs, and it contributes to research on teachers' cognition by providing a method for modeling their cognitive structures.

Keywords: statistics, teacher education, categorical data, statistical knowledge for teaching, partially correct constructs 


\section{Introduction}

Two related trends are apparent in regard to learning statistics. The first is a growing international consensus that students should begin to develop statistical and probabilistic reasoning before entering secondary school (Australian Education Council, 1994; Department for Education and Employment, 1999; Franklin et al., 2007; National Council of Teachers of Mathematics (NCTM), 2000; New Zealand Ministry of Education, 2010). The second is a growing recognition of the need to enhance teachers' abilities to teach statistics and probability (Batanero, Burrill, \& Reading, 2011). The first trend is fueled in large part by the importance of statistical ideas to everyday life. The second is motivated by research indicating that teachers' knowledge for teaching statistics and probability is often quite fragile (Stohl, 2005). Helping teachers build statistical knowledge is no small task, given that many of them have not experienced statistics courses that exemplify current curricular recommendations (Conference Board of the Mathematical Sciences, 2001; Metz, 2010).

In order to develop teachers' statistical knowledge, it is helpful to understand its structure. Research on the structure of teachers' knowledge can inform the design of teacher education curricula (Oliveira \& Hannula, 2008). At present, however, theories to guide research on teachers' statistical knowledge for teaching (SKT) are in early stages of development (Groth, 2007). Hence, in the present investigation, we aim to demonstrate how an existing theory of mathematical knowledge for teaching (MKT) (Hill, Ball, \& Schilling, 2008), the notion of partially correct constructs (PaCCs) (Ron, Dreyfus, \& Hershkowitz, 2010), and node-link diagrams for representing cognitive structures (Nesbit \& Adesope, 2006; Wheeldon \& Åhlberg, 2011) can work in tandem to contribute to a working model of SKT cognitive structures.

The notion of SKT rests on the premise that teachers need content-specific knowledge to guide instruction. This means that any discussion of SKT must be grounded in specific content that teachers are responsible for teaching. The theoretical analysis we present relates to the teaching of nominal categorical data handling and analysis. Many curriculum documents recommend that children's earliest experiences with statistics involve nominal categorical data. Young students are to gather data from classmates on questions such as, "What is your favorite beverage in the cafeteria?" (NCTM, 2000, p. 110) and "What is your 
favorite type of music?" (Franklin et al., 2007). They are then to make sense of the data using tools such as graphs and summary statistics. The prevalence of nominal categorical data analysis in the elementary grades makes it a relevant context for the study of SKT.

\section{Toward a model for mapping SKT}

The SKT mapping model we propose is based on the premise that knowledge development can be characterized in terms of a learner's construction of knowledge elements and relationships among them (Ron et al., 2010). Learners may produce individual constructs that reflect normative thinking, but constructs with idiosyncratic characteristics are also often produced. To model SKT, we propose that a means for identifying knowledge elements relevant to the domain must be used in tandem with a working theory of how the elements may be held in relation to one another. In the model to be developed, we employ a specific theory of MKT (Hill, Ball, \& Schilling, 2008) to identify knowledge elements relevant to SKT. Though mathematics and statistics can be considered distinct disciplines, the theory of MKT we employ has been profitably used in past discussions of SKT (Burgess, 2011; Godino, Ortiz, Roa, \& Wilhelmi, 2011; Groth, 2012; Wassong \& Biehler, 2010). After demonstrating the use of the MKT theory in identifying relevant elements of SKT, we use PaCC theory (Ron et al., 2010) to make conjectures about potential relationships individuals tend to construct among the elements.

\subsection{Identifying Relevant Knowledge Elements: Subject Matter Knowledge and Pedagogical Content Knowledge}

Hill, Ball, and Schilling (2008) theorized that MKT consists of two primary components: subject matter knowledge and pedagogical content knowledge. Existing studies of MKT provide tentative empirical links between teachers' MKT and their students' achievement (Hill, Rowan, \& Ball, 2005) and the mathematical quality of instruction students receive (Hill, Blunk, et al., 2008). Below, we consider how subject matter knowledge and pedagogical content knowledge may be manifested in teaching statistics in general and in the specific case of teaching children to analyze nominal categorical data. 
Subject matter knowledge can be conceptualized as consisting of common knowledge, specialized knowledge, and horizon knowledge (Hill, Ball, \& Schilling, 2008). Common knowledge is the content knowledge needed by teachers as well as other professionals. In statistics, common knowledge allows teachers to perform activities such as reading graphs, computing descriptive statistics, and designing statistical studies (Groth, 2007). Specialized knowledge, on the other hand, is specific to the teaching profession. It allows teachers to represent mathematical ideas in ways that are comprehensible to students. For instance, Watson (2008) described "hat plots," which can be used to help students transition from dot plots to more condensed box plot representations. Knowing about this statistical representation is desirable for teachers, but it is not necessarily relevant to other professions. Horizon knowledge allows teachers to know how topics are related over the entire span of the curriculum (Ball, Thames, \& Phelps, 2008, p. 403). When teachers first introduce nominal categorical data, for example, it is useful for them to know that students will, in later years, encounter ordinal categorical data. Having this knowledge makes it possible to avoid leading students toward overgeneralizations such as "categorical data categories can never be ordered."

Pedagogical content knowledge further distinguishes knowledge needed for teaching from that needed for other professions. It can be thought of in terms of knowledge of content and teaching, knowledge of curriculum, and knowledge of content and students (Hill, Ball, \& Schilling, 2008). Knowledge of content and teaching can be drawn upon to choose content-specific teaching strategies. In statistics, teachers with such knowledge might understand that the process of statistical investigation describes a mode of inquiry among professionals and also provides a framework for designing lessons (Franklin et al., 2007). Knowledge of curriculum may overlap with knowledge of content and teaching, but may also include knowing how content studied in one class relates to content in another (Shulman, 1987). The process of statistical investigation, for instance, may be used in mathematics class, but also has several connections to the process of scientific inquiry (National Research Council, 1996). Knowledge of content and students may include knowledge of specific student difficulties in learning content, students' developmental learning progressions, and ways students typically approach tasks (Hill, Ball, \& Schilling, 2008). Knowledge of content and 
students appears to be somewhat of a foundation for PCK, as researchers have found that it informs teaching moves and curricular decisions - teachers who participate in professional development focusing on knowledge of content and students tend to make teaching moves and curricular decisions associated with deeper student learning than those who do not (Carpenter, Fennema, Peterson, \& Carey, 1988; Carpenter, Fennema, Peterson, Chiang, \& Loef, 1989; Cobb et al., 1991).

Several elements of subject matter knowledge and PCK can be identified for the specific case of teaching elementary analysis of nominal categorical data. Pertinent subject matter knowledge includes the idea that the mode is a suitable measure for such data, and the mean and median are not (Yates, Moore, \& McCabe, 1999). Additionally, it is important to know that nominal categorical data categories, as opposed to ordinal categories, have an arbitrary order (Leavy, Friel, \& Mamer, 2009). PCK (more specifically, knowledge of content and students) includes recognizing that children may erroneously try to compute means and medians for category frequencies. Children may also erroneously attempt to order nominal categories using idiosyncratic rules (e.g., alphabetical order) to try to determine a median (Leavy et al., 2009). Teachers who know of such student tendencies are in a position to select and design teaching strategies and curricular approaches to address them.

\subsection{Modeling Relationships among Relevant Knowledge Elements: Partially Correct Constructs (PaCCs)}

Given past research on teachers' knowledge of data analysis and probability, it is not safe to assume that teachers' construction of subject matter knowledge and PCK for teaching elementary nominal categorical data analysis is a trivial matter. Teachers who have taken introductory statistics courses may still have impoverished conceptual and procedural knowledge of ideas such as mean, median, and mode (Groth \& Bergner, 2006). Research also suggests that teachers may not be cognizant of the differences between tools suitable for analyzing categorical data and those for quantitative data (Leavy, 2010). For instance, some teachers erroneously encourage students to compute the mean of category frequencies to summarize nominal categorical data (Franklin \& Mewborn, 2008). Hence, the literature suggests that many teachers have only partially constructed 
the content knowledge needed for teaching elementary nominal categorical data analysis.

Ron et al. (2010) provided a perspective on mapping partially correct constructs (PaCCs) held by individuals. They defined PaCCs as "constructs that only partially match some underlying mathematical knowledge elements" (p. 72). Their research identified three types of PaCCs. The first was a missing element $\mathrm{PaCC}$. Individuals with missing element PaCCs have constructed "some but not all of the constituents of the mathematical element" (p. 83). A second type was an incompatible element $\mathrm{PaCC}$. Incompatible element $\mathrm{PaCC}$ are formed "when a student's construct for a mathematical element includes some of the constituents of a mathematical element, but also includes a construct that contradicts at least one element" (p. 83). The third type, a disconnected element PaCC, occurs "when a student has constructed the constituent elements but fails to recognize or buildwith one of them as relevant when it is needed in a specific context" (p. 83). Ron et al. recommended that researchers identify additional examples of PaCCs, the types of PaCCs that appear frequently, and the patterns of PaCCs observed for specific curricular topics.

\section{Method for Empirically Grounding the SKT Model}

Ron et al. (2010) devised the PaCC theoretical model to analyze and explain individuals' thinking when inconsistent or unexpected answers to tasks were given. Likewise, our use of PaCCs was motivated by inconsistent and unexpected patterns of thinking we observed during an SKT-focused course we taught for prospective elementary school teachers. Next, we discuss our methods of providing empirical grounding for the proposed SKT model. This will include descriptions of the participants, the course in which they were enrolled, learning goals for the course, data gathering and analysis procedures, and the node-link diagrams we used to visually represent participants' SKT cognitive structures.

\subsection{Participants}

The theoretical model presented in this paper is grounded in empirical data collected from 31 prospective elementary and middle school teachers we taught in a newly instituted semester-long course. The course was designed for and taken by those who had not yet entered their student teaching practicum. Study 
participants were relative newcomers to the study of post-secondary statistics. Only 3 participants had taken an introductory post-secondary statistics course. One of the participants had taken an Advanced Placement (AP) course in statistics (College Board, 2008) in high school, but did not earn a high enough score on the examination to receive college credit. At the beginning of the semester, 29 of the participants took the Comprehensive Assessment of Outcomes in Statistics (CAOS) pre-test (delMas, Garfield, Ooms, \& Chance, 2007). CAOS is an assessment of students' conceptual understanding of ideas usually studied during a first course in post-secondary introductory statistics. Participants, on average, answered $34.9 \%$ of the items on the CAOS pre-test correctly. In contrast, delMas et al. reported a $44.9 \%$ correct answer rate on the pre-test for a sample of 763 introductory statistics students from several different institutions.

\subsection{Learning Goals for Participants and Associated Teaching Strategies}

The semester-long course providing the setting for the study was designed to help prospective teachers develop subject matter knowledge and PCK related to elementary nominal categorical data analysis. The specific intended knowledge elements participants were to develop related to this study are depicted in Figure 1. They were to understand that the mode is a suitable summary of nominal categorical data, but the mean and median are not. They were also to understand that the orderings of nominal categorical data categories are arbitrary, and to distinguish between category frequencies and quantitative data. In addition to these subject matter knowledge elements, they were to develop PCK. In particular, they were to recognize some common student errors related to handling and analyzing nominal categorical data and use that knowledge to select strategies likely to develop children's thinking. As they selected strategies, we wanted participants to avoid transmission-oriented approaches in favor of those that led children to analyze their own thinking, since transmission-oriented approaches are generally associated with lower levels of student achievement (Campbell, Kyriakides, Muijs, \& Robinson, 2004). 
Fig. 1 Intended knowledge elements related to knowledge for teaching elementary nominal categorical data analysis

We used several teaching strategies to help participants develop the intended knowledge elements. On the first day of the semester, participants conducted a "meet and greet" survey (Garfield \& Ben-Zvi, 2008), which prompted them to collect both categorical and quantitative data from their classmates (e.g., "What is your field of study?" and "How many credits are you taking this semester?"). The survey led to a class discussion of how the different types of data might be graphed and summarized. In another class session, participants were given the following prompt for group work from the course text (Perkowski \& Perkowski, 2007) after studying definitions and examples of different types of quantitative and categorical data:

1. Give two additional examples of nominal, interval, and ratio data. Explain why your examples fit each type.

2. Provide two examples of ordinal data: one that is numerical, and another that is categorical. Provide reasons for classifying these as ordinal data. (p. 15)

Participants also read and discussed a case about categorical data analysis in an elementary school classroom (Russell, Schifter, \& Bastable, 2002). The case raised issues involved in leading children's classroom discussions about nominal categorical data.

To supplement the in-class activities described above, participants were asked to individually read and respond to two teacher-oriented journal articles on nominal categorical data analysis. The first article (Franklin \& Mewborn, 2008) distinguished classroom activities and analyses suitable for categorical data from those for quantitative data (e.g., why computing the mean is suitable for quantitative data but not for nominal categorical data). It explained how each activity in the article illustrated recommendations from the Pre-K-12 Guidelines for Assessment and Instruction in Statistics Education (GAISE) report (Franklin et al., 2007). The second article (Leavy et al., 2009) described a classroom activity based on a Connected Mathematics Project lesson (Lappan, Fey, Fitzgerald, Friel, \& Phillips, 2006) with the goal of helping students distinguish between categorical and quantitative data. It explained how the classroom teacher dealt with students' erroneous idea that the median is suitable for nominal categorical 
data. Both articles described common patterns of students' thinking in connection with nominal categorical data analysis. Hence, the two readings aligned with the subject matter and PCK knowledge elements we wanted participants to develop.

\subsection{Data Gathering, Analysis, and Node-Link Diagrams}

Writing prompts were designed to gather data on participants' understanding of the two assigned teacher-oriented articles (Franklin \& Mewborn, 2008; Leavy et al., 2009). The writing prompts for the two articles are items 1-5 in the appendix. The prompts helped reveal aspects of participants' thinking as they were in the process of constructing the intended subject matter knowledge and PCK elements for the course. Writing prompts were used as a data collection method because of their empirically demonstrated ability to reveal aspects of students' mathematical and statistical thinking (Aspinwall \& Aspinwall, 2003; Groth, 2012; Groth \& Bergner, 2005; Miller, 1992). It should be noted that a limitation of using writing prompts to elicit thinking is that students sometimes do not express everything they know about any given item in writing (Aspinwall \& Aspinwall, 2003). This limitation was addressed to an extent because we told the participants in advance that depth of thought would be a criterion on which their writing would be assigned a homework grade. Although it is possible that there may still have been aspects of the participants' thinking that were not revealed in writing, we found the writing elicited with the prompts to be useful for guiding subsequent instruction. Several sample participant responses provided later in this report illustrate the level of detail of response obtained.

After responding to the writing prompts, participants completed an in-class individual examination with an item on identifying and addressing children's errors in analyzing nominal categorical data (item 6 in the appendix). The written responses to items 1-6 in the appendix were retained for analysis. The 31 study participants are those who answered all six items and provided permission for their responses to be analyzed for the study.

As responses to each of the six items shown in the appendix were written and submitted to us, we (the authors) read them and compared initial observations about the nature of participants' work with one another. As we did so, we noticed that several inconsistent and unexpected responses were given by participants. This motivated a more formal analysis of the responses. 
After the initial reading of participants' responses, a systematic withincase analysis of each participant's data was carried out. Ron et al. (2010) suggested comparing artifacts of student learning against the intended knowledge elements when analyzing and describing PaCCS. Accordingly, participant responses to the items shown in the appendix were analyzed for evidence of construction of the intended knowledge elements (Figure 1). Relationships among knowledge elements held by each participant were represented with node-link diagrams (Nesbit \& Adesope, 2006; Wheeldon \& Åhlberg, 2011). The nodes in each diagram contained descriptors of elements of subject matter knowledge and PCK elements evidenced in individual written responses. Links were used to illustrate how the elements were held in relation to one another. Our decision to use node link diagrams in this way was inspired by the node-link diagrams used by Ron et al. to explain the general structures of missing element, incompatible element, and disconnected element PaCCs. The node-link diagrams provided pictorial representations of the elements in participants' cognitive structures and relationships among them.

The node-link diagrams served several purposes during data analysis. First, they provided discursive objects for us. That is, interpretations of the data were refined as we discussed the matches between the node-link representations and participant data. Visual diagramming software (Inspiration, 2006) allowed for efficient revision of the diagrams as they were compared against the data. Second, the diagrams helped make our subjective assumptions explicit. In many studies, researchers have asked participants to draw node-link diagrams to understand the meanings they ascribe to ideas and connections they make across concepts (Daley et al., 2010; Nesbit \& Adesope, 2006). In a similar vein, we assembled the diagrams to provide readers a window to our own interpretations of the data. Subjectivity is inherent to the process of doing research, and node-link diagrams help depict researchers' beliefs about the data and relationships among ideas they perceive to be important (Daley, 2004; Groth, 2010). Figures 2-6 provide specific examples of node-link diagrams we assembled during data analysis.

We completed a cross-case analysis when node-link diagrams had been agreed upon for each individual participant. Because node-link diagrams condense data to a more manageable form, they facilitate the process of cross-case analysis (Daley, 2001). The individual node-link diagrams were compared against one 
another and clustered into categories having similar characteristics (Miles \& Huberman, 1994). Evidence of the three PaCC categories described by Ron et al. (2010) was sought during the clustering process, but the researchers also looked for groups of PaCCs that might extend or refine the three existing categories (missing element, incompatible element, and disconnected element). The categories that emerged during data analysis suggested families of SKT cognitive structures related to teaching nominal categorical data analysis.

\section{SKT Cognitive Structures Derived from Empirical Data}

During our cross-case analysis of PaCCs, four categories were identified. They were: (i) missing element (7 participants), (ii) incompatible element (5 participants), (iii) missing and incompatible element (4 participants), and (iv) disconnected element (10 participants). Along with these four categories of response, 5 participants showed evidence of having constructed all of the intended knowledge elements and linking relationships (Figure 1). Each category is described below by using exemplars from the data and discussing them in connection to other participants in the same $\mathrm{PaCC}$ category.

\subsection{Construction of all intended knowledge elements and relationships}

Figure 2 depicts the knowledge structure of a participant, Deanna (a pseudonym, as are the rest of the participant names) who showed evidence of having constructed all of the intended knowledge elements and linking relationships. Her node-link diagram had essentially the same structure as the four others judged to have constructed all intended knowledge elements and linking relationships. It provides a baseline against which other PaCC categories can be compared.

\section{$<$ INSERT FIGURE 2 HERE $>$}

Fig. 2 A depiction of Deanna's knowledge structure

Deanna's knowledge that category frequencies are not quantitative data and that nominal categorical data categories have arbitrary order contributed to the identification of both suitable and inappropriate measures of central tendency. She 
made a distinction between quantitative data and category frequencies in describing why students should not be asked to compute a mean for nominal categorical data, stating,

The mean requires having numerical values for the variable of interest.

With categorical values, only quality is subject to observation and recording (color, gender, etc) rather than numerical value. The mean of frequency, or how often that specific quality occurs in a given period of time or experimentation, has no significance to the original questions at hand.

Deanna was also able to devise an example to explain why nominal categorical data categories have arbitrary order. She said that the median is of no use if one is investigating class data compiled from individuals' responses to the question, "Which color jellybean is your favorite?" because "finding a midpoint is not possible; in terms of colors, yellow is no better than blue, which is no better than green." Along with recognizing mean and median as unsuitable measures for nominal categorical data, she acknowledged that the mode was a useful summary statistic.

Deanna also showed evidence of constructing knowledge of children's errors when interpreting nominal categorical data. She identified a student's attempt to order frequencies of eye color data (appendix item 6) to identify the median as problematic. Similarly, she identified student attempts to use frequencies to compute a mean as incorrect, stating that the "average of frequencies is possible...however...the average in this case tells nothing of the typical eye color." Additionally, Deanna identified a student attempt to order categories to compute a median as incorrect. She extended the jellybean example cited above to exemplify the error of ordering categories and identified student attempts to place eye color categories in a set order (appendix item 6) as incorrect.

Deanna also appropriated a strategy for helping children confront and revise errors in their thinking. One of the assigned articles (Leavy et al., 2009) described a strategy a teacher used to help children understand that the order of categories in nominal categorical data is arbitrary. The teacher asked children to compute the median when they placed an even number of categories in a given order. When they placed categories of pets in order and the categories of "fish" and "bird" were in the middle of the list, the teacher asked them if determining a 
median made sense. Children concluded that ordering the categories in such a case was not meaningful, since the "middle animal" would be a nonsensical category such as "fird." Deanna used the same questioning strategy when confronted with a situation where a student tried to order eye color categories to determine a median (appendix item 6). In response to the error, Deanna proposed asking, "What if the median fell between green and hazel?" and suggested the student may be prompted toward rejecting a nonsensical answer such as "grazel." Deanna provided examples of other situations in which the same strategy might be employed, such as placing categories of tools in order and having students potentially realize that the median between "screwdriver" and "wrench" would be a nonsensical answer like "scrench."

\subsection{Missing element PaCCs}

Missing element PaCCs were characterized by the fact that when participants had opportunities to demonstrate construction of intended knowledge elements, they did not do so. Two salient missing elements in some participants' thinking were the ideas that nominal categorical data categories have arbitrary order and that frequencies can be distinguished from quantitative data. Virtually every item in the appendix provided the opportunity to demonstrate construction of these elements, with the most direct opportunities occurring in items 4-6. Of course, it should be acknowledged that in this study, and with any data collection technique, participants may not reveal all knowledge they have constructed. Our conclusions are drawn on the basis of what we were able to observe in participants' responses to the items in the appendix.

Sarah's responses suggested a PaCC missing the element that nominal categorical data categories have arbitrary order (Figure 3). When asked to describe difficulties students may have in thinking about the median in relation to nominal categorical data (appendix items 3 and 4), she did not draw on the idea that the data categories have arbitrary order. Instead, she described instances where an even number of categories was present and explained that it would be more difficult to determine the median than in situations with an odd number of categories. Her thinking implied that it actually was possible to order categories meaningfully. When presented a situation where a student identified the middle category in a data display as the median (appendix item 6a), she stated, 
Peggy's answer is incorrect because the graph is not in sequential order. If it was, brown would be the median since one of its points is in the middle number of data points.

Hence, rather than rejecting the idea that nominal categorical data categories can be ordered for the purpose of determining the median, Sarah decided that the student needed to use a different ordering rule, not recognizing the underlying causes of student difficulty.

\section{<INSERT FIGURE 3 HERE>}

Fig. 3 A depiction of Sarah's missing element PaCC

The absence of the arbitrary order element did not prevent all participants from identifying computation of the median as a student error. Lori, for example, consistently stated that it was impossible to determine the median for nominal categorical data. However, none of the responses she provided to items 1-6 referenced the idea of order. When asked to provide an example of a data set for which the median could not be determined (appendix item 3), she replied, "A data set in which the median cannot be determined is favorite football team. Favorite football teams are a categorical/nominal data set and since it doesn't have numbers but a category it is impossible to find the median." Later, when presented a situation where a student identified a category displayed in the middle of a dotplot as the median (appendix item 6a), Lori stated that it was impossible to have a median for such data because there could potentially be two middle categories. The essence of her strategy for teaching children about the median and categorical data (appendix item 5) was to "explain why it is impossible to determine the median of a categorical data set, and then ask (the students) if they understood." Although the idea that the median is not suitable for nominal categorical data is correct, without developing the idea that such data categories have arbitrary order, she had little recourse but to teach the relationship between the median and nominal categorical data as a rule to be memorized without conceptual grounding. Janet and Tony exhibited similar patterns of thinking in that they were able to consistently recognize computation of a median for nominal categorical data as a student error, but ultimately selected transmission-oriented teaching strategies rather than those designed to help students analyze their own thinking. 
Another type of missing element $\mathrm{PaCC}$ involved failure to distinguish between category frequencies and quantitative data. Misunderstanding of the nature and purpose of category frequencies ultimately led Samantha to the conclusion that the mode was a frequency rather than a category when responding to item $6 \mathrm{~d}$. In responding to the item, she stated that a student was incorrect to believe the accompanying data set was bi-modal, even though the categories of "blue" and "brown" had the same frequency. She stated that the student instead should have identified "7" as the mode (the frequency of each of the modal categories). Donna and Jessica also did not include the distinction between category frequencies and quantitative data in their responses to items. However, unlike Samantha, they were able to recognize that the data set in item $6 \mathrm{~d}$ was bimodal. They were also able to recognize student attempts to compute the means and medians of frequencies for nominal categorical data as errors, but relied on their knowledge that such data categories have arbitrary order rather than the distinction between category frequencies and quantitative data to do so. For instance, in response to question $6 \mathrm{~b}$, which required participants to evaluate whether a student (Jordy) was correct to order category frequencies to determine a median, Donna stated,

Jordy is closer because he puts the data outcomes in order by number, however you still can't have a "meaningful” median with categorical data. I would explain to Jordy that although he put the data results in numerical order having green as the median doesn't make sense because you can't have a "middle" color, and if you do it has no meaning.

In earlier responses, Donna had explained that it makes no sense to have a "middle" category when the order in which nominal categories are presented is arbitrary. In essence, Donna and Jessica appeared to compensate for missing the distinction between frequencies and quantitative data by leaning on the knowledge that nominal categories have arbitrary order.

The missing element PaCCs illustrated a relationship between subject matter knowledge and PCK: for the study participants, missing one of the intended subject matter knowledge elements weakened responses to PCK-related tasks. As seen above, Sarah and Lori provided misleading directions for students that stemmed from missing elements in their own knowledge structures. Donna and Jessica did not provide misleading directions, but at the same time did not 
provide complete explanations of student errors and teaching strategies to address them.

\subsection{Incompatible element PaCCs}

Incompatible element $\mathrm{PaCCs}$ were evident when participants held contradictory ideas to be true. Joan's thinking (depicted in Figure 4) exemplified this PaCC type. Her knowledge structure strongly resembled Deanna's, with one important difference. At one point (appendix item 2), Joan identified the computation of means for categorical data as an error:

It is inappropriate to ask children to determine the mean of a set of categorical data because in order to find the mean you must have numerical values and categorical data is based off categories. Therefore, the mean has no significance to the original question or to the data. However, when asked to diagnose a student's work containing a related error (appendix item 6c), she stated,

Priscilla is correct. You can only find the mean or average of this data set because it is categorical. I would support her learning by sharing exactly what the average represents and allow her to think about what it means, and why it is a good representer of this data set.

This conflict in thinking was particularly surprising in light of Joan's consistent reasoning in other items that it was not meaningful to use category frequencies to compute medians. The presence of numbers for category frequencies in the student work sample item appeared to prompt Joan at least temporarily to set aside the idea that the mean was not suitable for nominal categorical data in favor of the notion that the mean is useful for any task involving numbers. One other participant, Judy, showed the same conflict between knowledge elements.

\section{<INSERT FIGURE 4 HERE $>$}

Fig. 4 A depiction of Joan's incompatible element PaCC

Situations involving the median also caused conflicting elements to appear in some participants' thinking. Stephanie, Courtney, and Laura acknowledged that nominal categorical data categories cannot be ordered meaningfully, but when presented with a pre-ordered display of such data (appendix item 6), they directed students to use it to determine a median. The presence of this conflict in Stephanie's thinking was particularly striking because it was evident within the 
responses to two consecutive parts of the same item (appendix items 6a and 6b). In response to the first part of the item, she stated,

Gray is not the median color because of its location on the graph. The colors are displayed in alphabetical order, which still does not make gray the median. This data is categorical, not quantitative, meaning there is no real reason for the order and there is no median.

Then, in response to the second part of the item, she stated,

Jordy did not arrange the data in a logical order because she just took the top number from each bar graph. The correct way would be to write out "blue" 7 times, "brown" 8 times, "gray" 4 times, etc. and then find the median.

Stephanie apparently did not recognize that the algorithm she recommended to Jordy implicitly involved ordering the color categories. Her failure to recognize the conflict in her diagnoses of children's work led to contradictory ideas for guiding their learning (i.e., guiding them to determine the median for nominal categorical data in one case but not another).

In summary, incompatible element PaCCs involved conflicts between intended knowledge elements that went unrecognized by participants. Seemingly contradictory notions were held in tandem. Knowledge exhibited in the context of responding to one item was not drawn upon in answering related items (or, at times, different parts of the same item). The unrecognized conflicts led them to design and select teaching strategies likely to mislead children learning about the mean, the median, and situations to which they are applicable.

\subsection{Missing and incompatible element PaCCs}

In some cases, missing elements and incompatible elements appeared in tandem in participants' thinking. Gwen, for example, did not show evidence of constructing the idea that nominal categorical data categories have arbitrary order, and she also did not show evidence of constructing a distinction between category frequencies and quantitative data (Figure 5). Even though she was missing both elements, she stated that the mean and median were not suitable for nominal categorical data in response to several items shown in the appendix. Her reasons for stating these ideas appeared, however, to be based on memorization and parroting of language, as in her description of student errors in regard to the median (appendix item 4): 
There are two types of student errors that occur when working with nominal categorical data: computing a numerical value for the median and computing a categorical [sic]. Numerical value is when numerical data, such as the heights of students or the number of children in families, are discussed as a data set. The median is useful as a marker of the midpoint of a distribution of data. The median cannot be used to summarize categorical data, such as favorite ice cream flavors for example. On the other hand, categorical median, students have problems formalizing the distinction between data types and without questioning whether the median could be used for all data types.

In this response, Gwen used language from the assigned article to try to explain the student misconceptions, but did not develop ideas related to arbitrary ordering of nominal categories and distinguishing category frequencies from quantitative data.

\section{<INSERT FIGURE 5 HERE>}

Fig. 5 A depiction of Gwen's missing and incompatible elements $\mathrm{PaCC}$

Gwen's fragile understanding of the basis for not computing the mean and median for nominal categorical data appeared to contribute to the manifestation of conflicting knowledge elements when she was asked to analyze children's work. When presented the work samples in appendix item 6 , she did not use her earlierstated rules that the mean and median are not suitable for categorical data. Instead, she provided analyses that conflicted with the rules. She said that it was correct for a student to put category frequencies in order to determine a median eye color (appendix item 6b). She also said it was correct for another student to compute the mean frequency for eye color (appendix item 6c). Because Gwen's construction of rules for the suitability of mean and median for categorical data were lacking a conceptual basis, she was vulnerable to making mistakes analyzing children's work when presented a situation where both pre-ordered categories and numbers were present. Her mistakes in diagnosing students' work prevented her from suggesting teaching strategies to help students confront and address their errors.

Corey, Ryan, and Sherry, like Gwen, did not show evidence of having constructed a distinction between quantitative data and category frequencies. The three of them also judged it to be correct for a student to determine a median for nominal categorical data despite declarative statements to the contrary in response to some items. For each missing and incompatible element $\mathrm{PaCC}$, participants 
were not able to apply incompletely grounded declarative knowledge to the analysis and resolution of student errors.

\subsection{Disconnected element PaCCs}

Some of the participants who did construct most of the intended knowledge elements and linking relationships did not appropriate ideas for teaching from the assigned articles to help students confront and revise errors in thinking. Ten participants' knowledge structures strongly resembled Deanna's (Figure 2) in most aspects. However, rather than building on or appropriating teaching strategies designed to prompt students to identify their own errors, these ten participants favored directly transmitting their content knowledge to children. Rosie's case is typical (Figure 6). To address a student's error of ordering categories to compute a median (appendix item 6a), Rosie proposed:

I would explain to Peggy that categorical data does not have a median because the labels of categorical data, for example colors, can be arranged in any order and still represent the same data. Therefore, there is no logical middle (median) of a categorical data set.

Rosie handled the rest of the student errors shown in item 6 in a similar fashion, electing to directly explain to students why their answers were incorrect. This teaching strategy, unlike some of those described earlier, would not mislead students. However, Rosie's knowledge is best characterized as a disconnected element $\mathrm{PaCC}$ because the requisite knowledge elements she had constructed were not drawn upon to help construct the targeted knowledge element of teaching in a manner to lead students toward recognizing and remedying their own errors.

\section{<INSERT FIGURE 6 HERE>}

Fig. 6 A depiction of Rosie's disconnected element PaCC

\section{Discussion}

Our aim in this exposition has been to propose and illustrate a model for mapping SKT cognitive structures. The model has the potential to supplement quantitative instruments related to content knowledge for teaching (e.g., Hill, Ball, \& Schilling, 2008) because it does not simply assign a scale score to teachers' knowledge. Instead, it represents qualitative relationships among individual 
teachers' knowledge elements and provides a means for comparing individuals' cognitive constructs against one another. This sort of representation helps reveal conflicts within cognitive structures along with missing and disconnected elements. Such information has the potential to inform the day-to-day decisions of teacher educators in designing learning experiences and to provide researchers a means for conducting fine-grained analyses of teachers' SKT.

Although the model we presented was grounded in analyses of SKT cognitive structures, it seems likely to be just as applicable to investigations of MKT. Mathematics and statistics can be considered distinct disciplines, but our analysis was not constrained to non-mathematical elements of the discipline of statistics. Additionally, the relevant elements in the cognitive structures and the goals for the course in which they were to develop trace back to a theory of MKT (Hill, Ball, \& Schilling, 2008). As this MKT theory has been used to assess teachers' knowledge in areas such as number and operations, algebra, and geometry, it appears to have potential to identify relevant knowledge elements in those mathematical domains as well.

Of course, the MKT theory we employed has its own limitations. Hill, Ball, and Schilling (2008) acknowledged that the theory is still in development and is likely to be for some time. Since our model is partially built on this theory, it, too, should be considered open to further development. Future iterations of the model may rely on revisions to the Hill, Ball, and Schilling model for the purpose of identifying knowledge elements relevant to SKT (and possibly MKT). Alternatively, competing theories of the relevant elements of SKT and MKT may, in the future, serve the purpose of identifying relevant knowledge elements to be assessed and developed. The state of flux in the domain of SKT and MKT knowledge development at present necessitate that this be considered a living and developing model rather than one in which all particulars are wholly determined and fixed. Re-visiting the model in light of continuing developments in MKT and SKT research is likely to improve it.

Another open question about the model relates to the stability of the PaCC structures we observed. Ideally, we would like cognitive structures resembling Deanna's to be stable and transferrable to her teaching, and for structures with missing, incompatible, and disconnected elements to be more amenable to change. At present, we are not in a position to make claims about the stability and 
transferability of the structures we observed. However, our model does provide tools to facilitate such analyses. PaCC maps produced at different points in a prospective teacher's preparation could contribute to the study of how cognitive structures change (or remain fixed) through phases such as admission to a program, initial content courses, methods courses, and practicum (or phases relevant to preparation programs with different structures). It may also be profitable to study how prospective teachers' cognitive structures change (or remain fixed) when confronted with $\mathrm{PaCC}$ node-link diagrams representing their own thinking. Such experiences may encourage metacognitive activity by prompting individuals to reconcile conflicting elements of thinking, or alternatively they may have no effect on an individual's knowledge development. Although we make no claims about the stability of the PaCCs we observed, our model provides a tool for investigating several questions of this nature about stability and transferability.

As the model is used to investigate additional questions about MKT and SKT, consideration can be given to using types of empirical data beyond those we gathered. For instance, Hill, Blunk, et al. (2008) analyzed classroom video from lessons teachers taught and teacher interviews to make inferences about teachers' MKT. Ron et al. (2010) used video of learners working in pairs and participating in classroom discussions to understand the nature of the PaCCs they constructed. Since our model is built on the MKT and PaCC theories undergirding these previous studies, future research employing our model may benefit from gathering these additional types of data. Data from intensive interviews that probe participants' thinking, for example, may help further explain why some elements in cognitive structures conflict with one another. Classroom video taken after prospective teachers have completed their undergraduate programs may help answer questions about the resiliency and transferability of the PaCCs they construct when first developing subject matter knowledge for teaching. Although our model was developed in conjunction with a specific set of tasks and data gathering strategies, its use is not necessarily constrained to them. Gathering additional empirical data may also help refine our proposed model. Such data might reveal new connections or conflicts between the underlying MKT and $\mathrm{PaCC}$ theories that were not suggested by the data we gathered. 


\section{Conclusion}

Much remains to be done in regard to mapping SKT and MKT, assessing them, and devising related teacher education curricula. The present study contributes to the effort by suggesting a model to help illuminate relationships among teachers' knowledge elements and inform theory, research, and the design of teacher education. The PaCC mapping scheme in conjunction with MKT theory and node-link diagrams provides a mechanism for drawing out subtle links and contradictions among knowledge elements that may be difficult to detect with quantitative instruments that rely mainly on multiple-choice items (e.g., Hill, Ball, \& Schilling, 2008). Going forward, it will be important to map knowledge related to other areas essential to teaching children statistics and mathematics, to continue to test the proposed model with empirical data, and to investigate optimal means for developing resilient subject matter knowledge and PCK elements in tandem.

\section{References}

Aspinwall, L., \& Aspinwall, J.S. (2003). Investigating mathematical thinking using open writing prompts. Mathematics Teaching in the Middle School, 8, 350-353.

Australian Education Council. (1994). Mathematics: A curriculum profile for Australian schools. Melbourne: Curriculum Corporation.

Ball, D.L., Thames, M.H., \& Phelps, G. (2008). Content knowledge for teaching: What makes it special? Journal of Teacher Education, 59, 389-407.

Batanero, C., Burrill, G., \& Reading, C. (Eds.) (2011). Teaching statistics in school mathematics Challenges for teaching and teacher education: A joint ICMI/IASE study. New York: Springer.

Burgess, T.A. (2011). Teacher knowledge of and for statistical investigations. In C. Batanero, G. Burrill, \& C. Reading (Eds.), Teaching statistics in school mathematics - Challenges for teaching and teacher education: A joint ICMI/IASE study (pp. 259-270). New York: Springer.

Campbell, J., Kyriakides, L., Muijs, D., \& Robinson, W. (2004). Assessing teacher effectiveness: Developing a differentiated model. London: Taylor \& Francis.

Carpenter, T.P., Fennema, E., Peterson, P.L., \& Carey, D.A. (1988). Teachers’ pedagogical content knowledge of students' problem solving in elementary arithmetic. Journal for Research in Mathematics Education, 19, 29-37.

Carpenter, T.P., Fennema, E., Peterson, P.L., Chiang, C., \& Loef, M. (1989). Using knowledge of children's mathematics thinking in classroom teaching: An experimental study. American Educational Research Journal, 26, 499-531. 
Cobb, P., Wood, T., Yackel, E., Nicholls, J., Wheatley, G., Trigatti, B., \& Perlwitz, M. (1991). Assessment of a problem-centered second-grade mathematics project. Journal for Research in Mathematics Education, 22, 3-29.

College Board. (2008). AP Statistics course description. Retrieved from http://apcentral.collegeboard.com/

Conference Board of the Mathematical Sciences. (2001). The mathematical education of teachers. Providence, RI: American Mathematical Society.

Daley, B.J. (2001). Learning and professional practice: A study of four professions. Adult Education Quarterly, 52, 39-54.

Daley, B.J. (2004). Using concept maps in qualitative research. In A.J. Cañas, J.D. Novak, \& F.M. González (Eds.), Concept maps: Theory, methodology, technology: Proceedings of the First International Conference on Concept Mapping (Vol. 1, pp. 191-197). Pamplona, Spain: Universidad Pública de Navarra.

Daley, B.J., Conceicão, S.C.O., Mina, L., Altman, B.A., Baldor, M., \& Brown, J. (2010). Concept mapping: A strategy to support the development of practice, research, and theory within human resource development. Human Resource Development Review, 9, 357-384.

delMas, R., Garfield, J., Ooms, A., \& Chance, B. (2007). Assessing students' conceptual understanding after a first course in statistics. Statistics Education Research Journal, 6(2), 2853. Retrieved from http://www.stat.auckland.ac.nz/ iase/serj/SERJ6\%282\%29 delMas.pdf

Department for Education and Employment. (1999). The national curriculum: Mathematics. London: Author

Franklin, C., Kader, G., Mewborn, D., Moreno, J., Peck, R., Perry, M., \& Scheaffer, R. (2007). Guidelines for assessment and instruction in statistics education (GAISE) report. Alexandria, VA: American Statistical Association.

Franklin, C., \& Mewborn, D.S. (2008). Statistics in the elementary grades: Exploring distributions of data. Teaching Children Mathematics, 15, 10-16.

Garfield, J.B., \& Ben-Zvi, D. (2008). Developing students'statistical reasoning: Connecting research and teaching practice. New York: Springer.

Godino, J.D., Ortiz, J.J., Roa, R., \& Wilhelmi, M.R. (2011). Models for statistical pedagogical knowledge. In C. Batanero, G. Burrill, \& C. Reading (Eds.), Teaching statistics in school mathematics - Challenges for teaching and teacher education (pp. 271-282). Dordrecht: Springer.

Groth, R.E. (2007). Toward a conceptualization of statistical knowledge for teaching. Journal for Research in Mathematics Education, 38, 427-437.

Groth, R.E. (2010). Interactions among knowledge, beliefs, and goals in framing a qualitative study in statistics education. Journal of Statistics Education, 18(1), Retrieved from http://www.amstat.org/publications/jse/v18n1/groth.pdf

Groth, R.E. (2012). The role of writing prompts in a statistical knowledge for teaching course. Mathematics Teacher Educator, 1, 23-40. Retrieved from http://www.nctm.org/publications/article.aspx?id=33985 
Groth, R.E., \& Bergner, J.A. (2005). Pre-service elementary school teachers' metaphors for the concept of statistical sample. Statistics Education Research Journal, 4(2), 27-42. Retrieved from http://www.stat.auckland.ac.nz/ iase/serj/SERJ4\%282\%29 groth bergner.pdf

Groth, R.E., \& Bergner, J.A. (2006). Preservice elementary teachers' conceptual and procedural knowledge of mean, median, and mode. Mathematical Thinking and Learning, 8, 37-63.

Hill, H.C., Ball, D.L., \& Schilling, S.G. (2008). Unpacking pedagogical content knowledge: Conceptualizing and measuring teachers' topic-specific knowledge of students. Journal for Research in Mathematics Education, 39, 372-200.

Hill, H.C., Blunk, M.L., Charalambos, Y., Lewis, J.M., Phelps, G.C., Sleep, L., \& Ball, D.L. (2008). Mathematical knowledge for teaching and the mathematical quality of instruction: An exploratory study. Cognition and Instruction, 26, 430-511.

Hill, H.C., Rowan, B., \& Ball, D.L. (2005) Effects of teachers' mathematical knowledge for teaching on student achievement. American Educational Research Journal, 42, 371-406.

Inspiration (Version 8) [software]. (2006). Philadelphia: Halcyon Software.

Lappan, G., Fey, J.T., Fitzgerald, W., Friel, S.N., \& Phillips, E. (2006). Data about us. Boston, MA: Prentice Hall.

Leavy, A.M. (2010). The challenge of preparing preservice teachers to teach informal inferential reasoning. Statistics Education Research Journal, 9(1), 46-67. Retrieved from http://www.stat.auckland.ac.nz/ iase/serj/SERJ9\%281\%29_Leavy.pdf

Leavy, A.M., Friel, S.N., \& Mamer, J.D. (2009). It's a fird! Can you compute a median of categorical data? Mathematics Teaching in the Middle School, 14, 344-351.

Metz, M.L. (2010). Using GAISE and NCTM Standards as frameworks for teaching probability and statistics to pre-service elementary and middle school mathematics teachers. Journal of Statistics Education, 18(3), Retrieved from www.amstat.org/publications/jse/v18n3/metz.pdf.

Miles, M.B., \& Huberman, A.M. (1994). Qualitative data analysis (2 ${ }^{\text {nd }}$ ed.). Thousand Oaks, CA: Sage.

Miller, D.L. (1992). Teacher benefits from using impromptu writing prompts in algebra classes. Journal for Research in Mathematics Education, 23, 329-340.

National Council of Teachers of Mathematics. (2000). Principles and standards for school mathematics. Reston, VA: Author.

National Research Council. (1996). National Science Education Standards. Washington, D.C.: National Academy Press.

Nesbit, J.C., \& Adesope, O.O. (2006). Learning with concept and knowledge maps: A metaanalysis. Review of Educational Research, 76, 413-448.

New Zealand Ministry of Education. (2010). New Zealand curriculum: Mathematics and statistics. Retrieved from http://nzcurriculum.tki.org.nz/Curriculum-documents/The-New-ZealandCurriculum/Learning-areas/Mathematics-and-statistics

Oliveira, H., \& Hannula, M.S. (2008). Individual prospective mathematics teachers. In K. Krainer $\&$ T. Wood (Eds.), The international handbook of mathematics teacher education (Vol. 3, pp. 13-34). Rotterdam, The Netherlands: Sense Publishers. 
Perkowski, D.A., \& Perkowski, M. (2007). Data and probability connections: Mathematics for middle school teachers. Upper Saddle River, NJ: Pearson.

Ron, G., Dreyfus, T., \& Hershkowitz, R. (2010). Partially correct constructs illuminate students' inconsistent answers. Educational Studies in Mathematics, 75, 65-87.

Russell, S.J., Schifter, D., \& Bastable, V. (2002). Developing mathematical ideas: Working with data. Parsippany, NJ: Dale Seymour Publications.

Shulman, L.S. (1987). Knowledge and teaching: Foundations of the new reform. Harvard Educational Review, 57, 1-22.

Stohl, H. (2005). Probability in teacher education and development. In G.A. Jones (Ed.), Exploring probability in school: Challenges for teaching and learning (pp. 345-366). Dordrecht: Kluwer.

Wassong, T., \& Biehler, R. (2010). A model for teacher knowledge as a basis for online courses for professional development of statistics teachers. In C. Reading (Ed.), Data and context in statistics education: Towards an evidence-based society. Proceedings of the Eighth International Conference on Teaching Statistics (ICOTS8, July, 2010), Ljubljana, Slovenia.

Watson, J.M. (2008). Exploring beginning inference with novice grade 7 students. Statistics Education Research Journal, 7(2), 59-82. Retrieved from http://www.stat.auckland.ac.nz/ iase/serj/SERJ7\%282\%29 Watson.pdf

Wheeldon, J., \& Åhlberg, M.K. (2011). Visualizing social science research: Maps, methods, and meaning. Los Angeles, CA: Sage.

Yates, D.S., Moore, D.S., \& McCabe, G.P. (1999). The practice of statistics. New York: W.H. Freeman and Company.

\section{Appendix}

\section{Assignment 1}

Article to read: Franklin, C.A., \& Mewborn, D.S. (2008). Statistics in the elementary grades: Exploring distributions of data. Teaching Children Mathematics, 15, 10-16.

1. Explain the difference between categorical and quantitative data. Give your own example of a statistical question that young students could investigate involving categorical data. Also give your own example of a statistical question that young students could investigate involving quantitative data.

2. On p. 13, the authors stated, "it is inappropriate to ask children to determine the mean of a set of categorical data." Why is it inappropriate?

\section{Assignment 2}

Article to read: Leavy, A.M., Friel, S.N., \& Mamer, J.D. (2009). It's a fird! Can you compute a median of categorical data? Mathematics Teaching in the Middle School, 14, 344-351.

3. Provide your own example of a data set for which the median cannot be determined. Then provide your own example of a data set for which the median can be determined. Explain your thinking. 
4. Describe two types of student errors that occur when working with nominal categorical data: computing a numerical value for the median and computing a categorical median. Illustrate how the two errors can occur using a data set of your own.

5. In 200-250 words, describe a general strategy you would use for teaching young students that you cannot find the median of categorical data and how you would assess their understanding. Then provide a rationale for your general strategy.

\section{$\underline{\text { Test Item }}$}

6. A group of elementary school students took a poll about the eye colors of people in their class. The graph they produced is shown below, along with some students' comments about the graph. Explain why each comment is correct or incorrect. Also describe what you would say in response to each student to help support his or her learning.

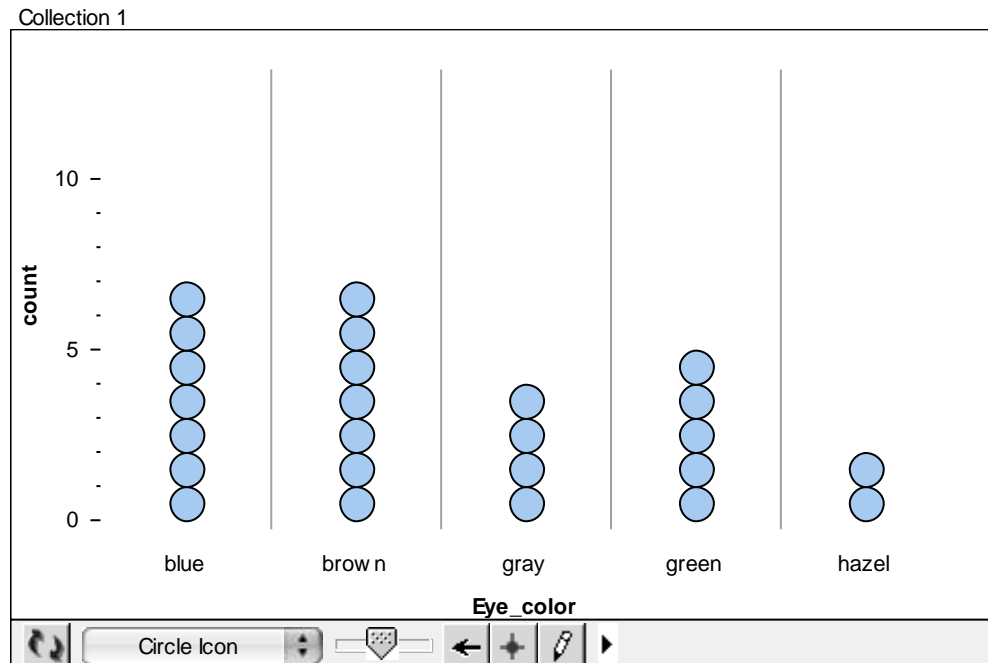

A. Peggy said, "Gray is the median color because it is right in the middle of all of the colors in our graph."

B. Jordy said, "There are 7 blues, 7 browns, 4 grays, 5 greens, and 2 hazels. If you put those numbers in order, you get 2, 4, 5, 7, and 7. The median is 5. So, green is the median."

C. Priscilla said, "Peggy and Jordy are both wrong. There is no median for the data set. You can only do an average. So, take the frequencies $(2,4,5,7$, and 7$)$, add them all up $(2+4+5+7+7=$ $25)$, and then divide by how many colors there are $(25 \div 5=5)$. You get an average of 5."

D. Joseph said, "There are two modes on the graph: Blue and brown. So, blue and brown are typical eye colors for people in our class." 
Figure 1

\begin{tabular}{|c|c|}
\hline \multicolumn{1}{|c|}{ Categorical data analysis } & \multicolumn{1}{|c|}{ Children's thinking } \\
Nominal categorical data categories have arbitrary order & A common student error is to compute of median of \\
Mode is suitable for nominal categorical data & A common student error is to compute mean of \\
frequencies & $\begin{array}{c}\text { A common student error is to attempt to order } \\
\text { Median is not suitable for nominal categorical data } \\
\text { Mean is not suitable for nominal categorical data } \\
\text { Category frequencies are not quantitative data }\end{array}$
\end{tabular}


Figure 2

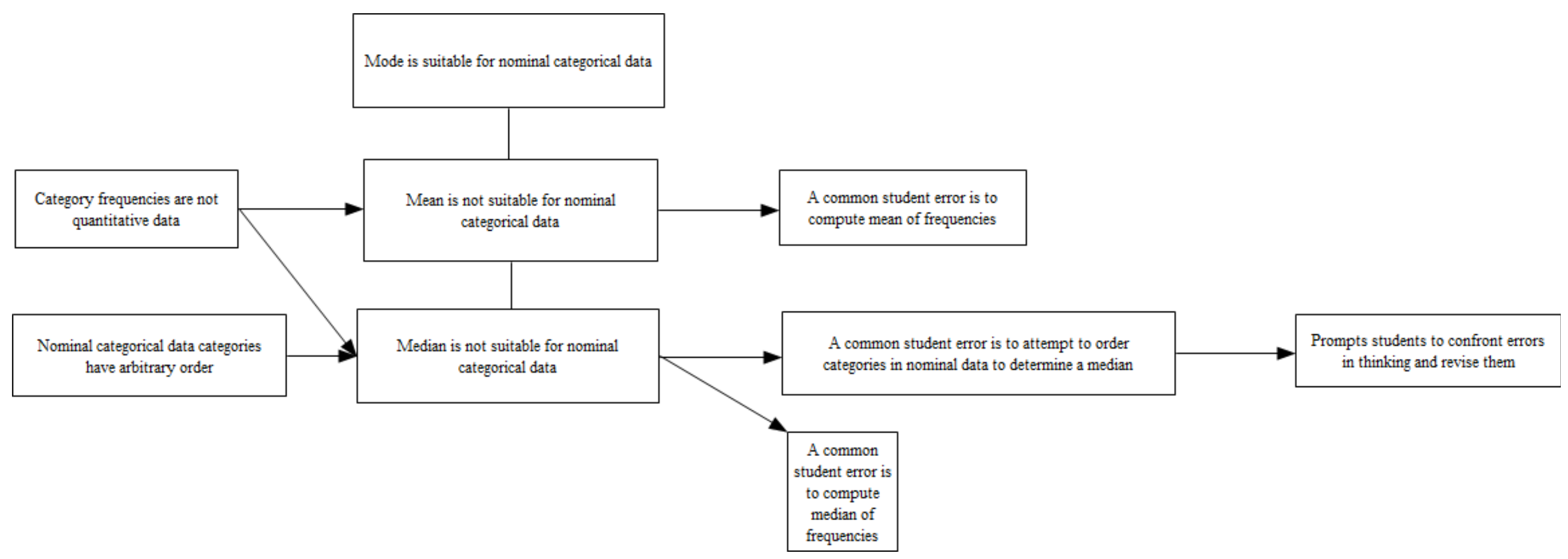

$\underline{\text { Key }}$

: Intended knowledge element constructed by participant

$\rightarrow$ : Element at tail of arrow contributes to element at tip of arrow 
Figure 3

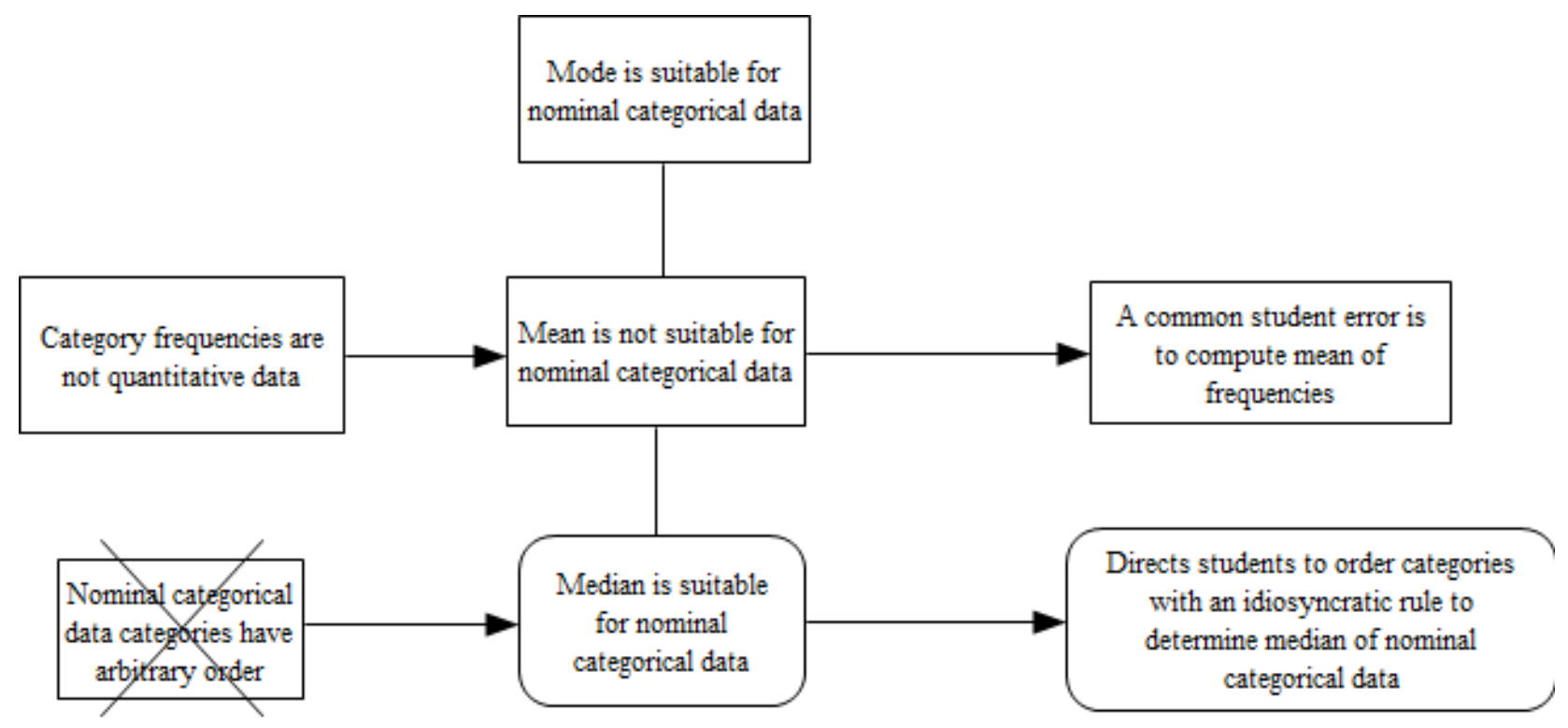

$\underline{\text { Key }}$

: Intended knowledge element constructed by participant

$\rightarrow$ : Element at tail of arrow contributes to element at tip of arrow

: Intended knowledge element not constructed by participant

$\square$ : Unintended element constructed by participant 
Figure 4

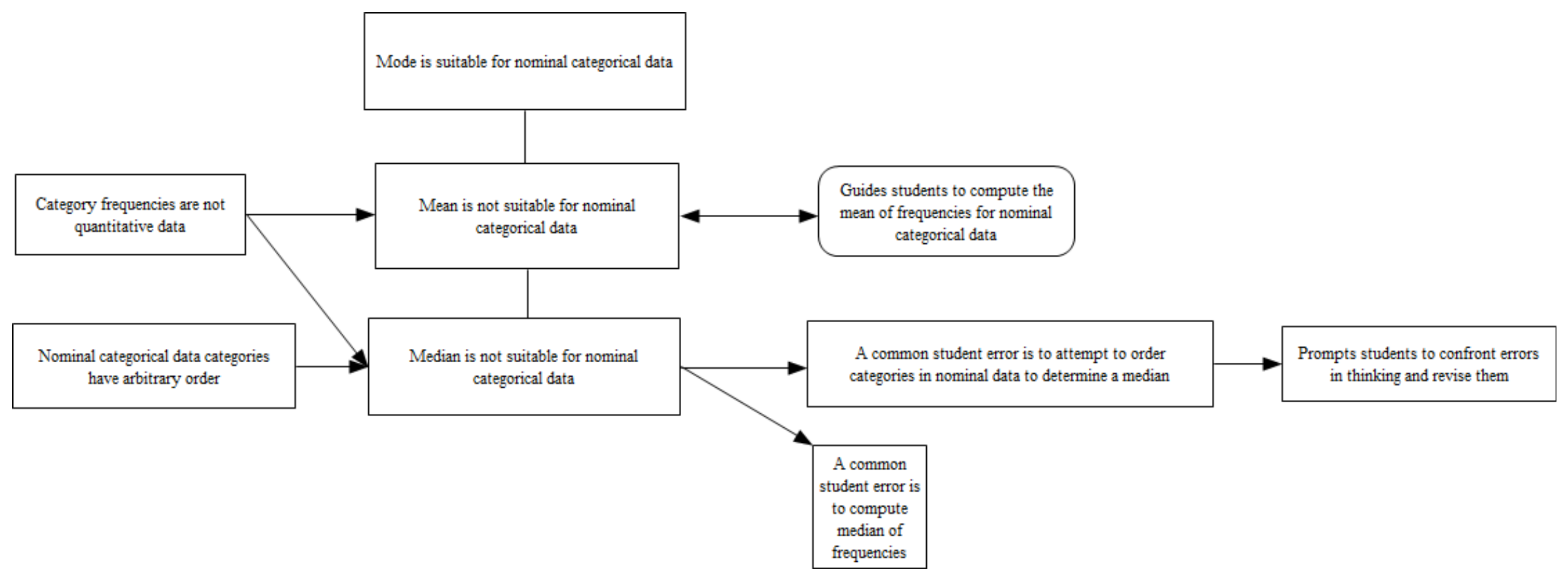

$\underline{\text { Key }}$

$\square$ : Intended knowledge element constructed by participant

$\rightarrow$ : Element at tail of arrow contributes to element at tip of arrow

$\leftrightarrow$ : Elements at tips of arrows are contradictory

$\square$ : Unintended element constructed by participant 

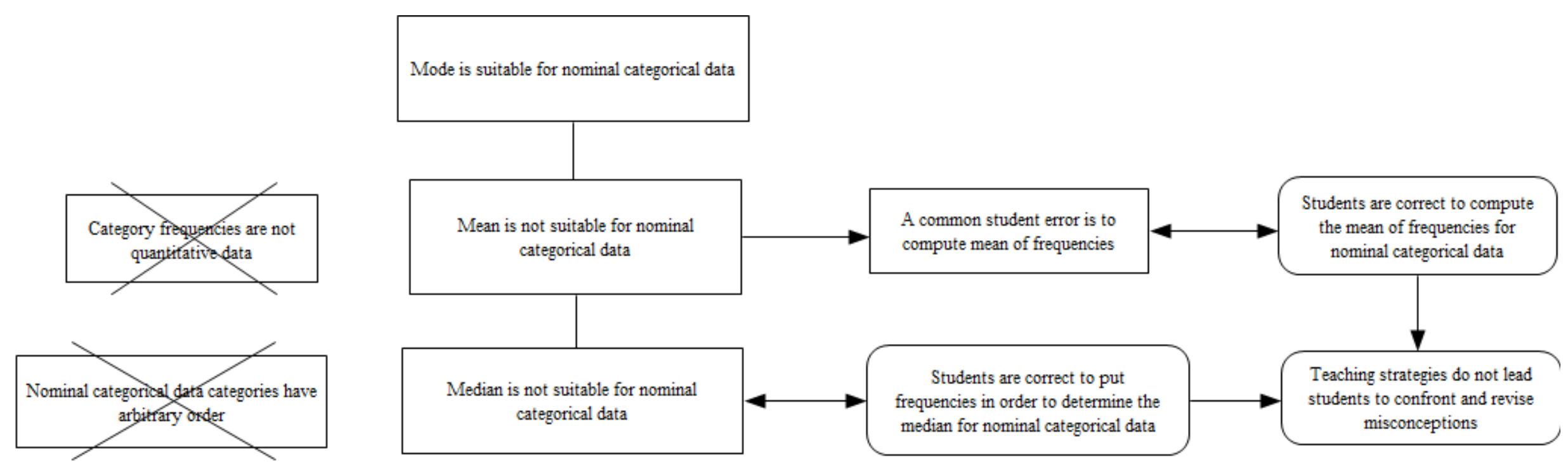

\section{$\underline{\text { Key }}$}

: Intended knowledge element constructed by participant

$\rightarrow$ : Element at tail of arrow contributes to knowledge element at tip of arrow

$\leftrightarrow$ : Elements at tips of arrows are contradictory

: Intended knowledge element not constructed by participant

: Unintended element constructed by participant 


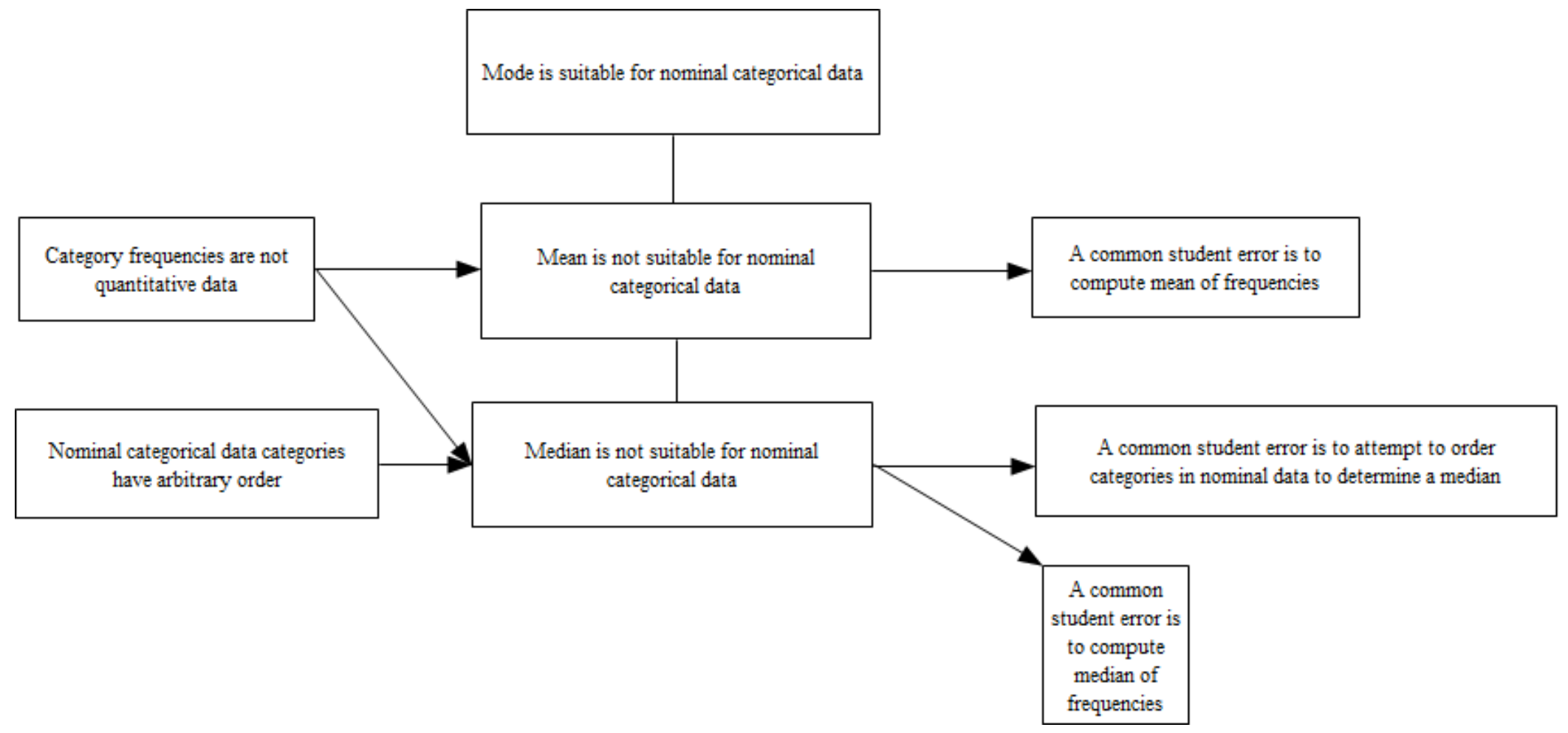

$\rightarrow$ : Element at tail of arrow contributes to element at tip of arrow

$\square$ : Unintended element constructed by participant 